\title{
Urban conditions impacting on the perception of security. A few Italian case studies
}

\author{
Maria Cristina Treu*
}

\begin{abstract}
Insecurity has always been linked to the fear of violent action against life and property, and the dangers of natural and anthropic catastrophes. To this we must now add the fear induced by a zero-interest economic and financial crisis, emphasized by a loosening of community ties. In this context, perceived insecurity can be ascribed to cross-cutting factors pertaining to gaps in income, age, education and employability, as well as to the recent migration waves and terrorist attacks. At the EU's behest, to further explore other specific issues shaping the perception of insecurity in small to medium-sized towns, The Fondazione del Politecnico di Milano has conducted a research on two smaller centers - a typical historic town and a typical Italian small municipality. The research, completed in November 2015 and validated by the EU in July 2016, has shown as common causes of perceived insecurity in urban areas the presence of disused property and material and social degradation, as well as a limited propensity to invest in urban regeneration. More specific causes have emerged, reflecting issues of self-regeneration (in the Aristotelian sense of entelechia), and a perceived lack of opportunities. The survey also identified a widespread opportunity for development in the recovery of local history and potential, and the implementation of programs aimed at land and urban generation, with an eye to the tightening of community ties.
\end{abstract}

Keywords: Old and new fears, Perception of security, Vulnerability in land and urban settlements, Behavioral critical issues, Urban regeneration

\section{Background}

Before discussing the survey, some interpretative issues regarding perceived insecurity and new fears must be addressed (Augè 2013).

Firstly, it must be stressed that there is no such thing as total security, and humankind has always had to contend with some degree of vulnerability in land and urban settlements. The last decades have seen a rise of the so called "urban sprawl" (Véron 2008), a mixture of excellence and growing social and living marginalization. In the modern megacities of our urbanized world (Augè 2008), growing income gaps and solidarity-hindering individualism feed fear, especially in social groups disadvantaged in terms of education, employability, income and age.

In this context, security must be regarded as a public asset, a common resource essential to a community's

*Correspondence: mariacristina.treu@polimi.it Dipartimento di Architettura e Studi Urbani, Politecnico di Milano, Via Bonardi 3, 20133 Milan, Italy living standards, and the quality of settlements and social ties has the same importance as crime prevention. Cities require attention, together with their growing suburban sprawl and constellation of smaller towns: development programs must be studied, side by side with policies of integrated prevention against those issues generating insecurity and fear, and requiring aim-specific policies of urban regeneration and renewal.

In the vast post-modern urban sprawls, dreams, fears, wishes and fashions are shaping the fabric of a new kind of city, where the needs of the global market mesh with the strategic reconversion of production; and where different urban environments are tied through a dramatization of architecture, the chances of new network economies, the relationships between urban spaces and their inhabitants, and the contradictions of those who would experience the city unconditionally (Amendola 2003, 2015).

In a context of growing everyday fear, both the market and the state show their limits-the former in the 
privatization of paid security, the second in strategies that emphasize alarm and threats, while skirting the seriousness and singularity of the issue (Battistelli 2008, 2016).

Perceived fear of violent actions against life and property results from both the general context and individual behavior. Criminal Law ranks such actions by gravity, including homicide and theft. Particular events may result in emphasis on specific crimes, and a stirring of fears old and new, such as that of violence against women, migration or terrorist attacks.

A globalization of major crime can be defined here through the relevant statistical data for major capitals, routes, and high-risk situations in European or extraEuropean regions and larger metropolitan areas.

On the other hand, also impacting on fear are environmental hazards and the dangers of earthquakes, flooding and landslides-especially in the wake of catastrophic events (Treu 2009). A further, asymmetric source of fear can be found in phobias, such as a fear of flying, or the often overlooked (although, in view of the higher rate of deadly accidents, more concrete) fear of driving.

"Perceived insecurity" is a tool meant to explore situations that are not technically criminal, physical and behavioral critical issues existing in the very fabric of urban communities, as well as in the neighborhoods of industrial outskirts or newer sprawls. Such conditions have grown more and more diversified: the expanding city is an uneven mixture of excellence spots and deteriorated areas, renewed and disposal neighborhoods, as well as industrial, service or artisanal property either still productive or new and never used, and abandoned construction sites. Park-and-ride stations must also be taken into account, such as railway stations or parking areas adjoining the hard-mobility networks or shopping malls. The phenomenon of perceived insecurity cannot be entirely eliminated, even in very crowded places. ${ }^{1}$

Beside each city's specific characters, perceived insecurity can be ascribed to present-day economic and social issues, as well as to the dangers of widespread petty crime. This is often statistically non relevant, but can be documented through local circumstantial inquiries or surveys in cities, towns, schools, and unsafe neighborhoods.

This is indeed the second topic of the INNES project, aimed at exploring whether specific factors can shape the perception of security by the inhabitants of Mantova and

\footnotetext{
${ }^{1}$ Thucydides shows how crowded places can be just as unsafe as deserted ones in a story dating back to 411 b.C. Athens: the oligarch Phrynicus was stabbed to death by a guardsman in the crowded Agora (Luciano Canfora in Corriere della Sera (La lettura), 9 August 2015).
}

Pegognaga-two smaller towns, a typical Italian historic town, and an urban-sprawl town. ${ }^{2}$

The survey, conducted by both quantitative and qualitative criteria, takes into account the approaches first outlined by several urban planning students (Cardia and Bottigelli 2011), the local security policies of Regione Emilia e Romagna's project Città Sicure (Calaresu 2013), and the Italian Police's new intervention guidelines, adapting to the new forms of petty crime through preventive action and the involvement of victims (Karrer 2003).

\section{Interpretive context and rediscovery of tangible and intangible common assets}

The survey concerns a context of punitive regulation aimed at containing the risks of social coexistence, in a society oriented towards actions of societal control, rather than positive values. A costly and ineffective approach.

Even solidarity is no longer based on positive belonging, but has its roots in a general feeling of fear, emphasized by the individual citizen's perceived isolation. Alternative courses of action are often rejected for the sake of efficiency, driven by a tendency, common in statistics and information, to emphasize crime and deviant behavior (Beck 1986; Bauman 1999, 2002). This is true of Italy too. Even discounting the differences in criminal prosecution, statistical systems and law, Italy compares favorably to the higher crime rates (See Fig. 1).

"Safe town" policies aimed towards risk-control cater to the citizen's wish for a life centered on safe routines. The outcome is enhanced societal control, sometimes beyond the bounds of legality - an approach that, instead of dealing with the phenomenon at its roots, strengthens the invisible but very effective barriers dividing neighborhoods, families and individual citizens.

Several studies and experiments, identifying priorities of social intervention, and prevention over repression, play a significant role in the empirical development of the concept of security through qualitative analysis of crime in urban neighborhoods and large metropolitan areas. Both the research initiated by the Association of Italian Municipalities (ANCI) and Regione Toscana among others, and the social and preventive policies tested in Turin, Venice, Padua, Modena, Bologna and Bari under the coordination of Massimo Pavarini (2006), promote initiatives aimed at strengthening neighborhood ties and intercultural socialization, as well as prevention policies involving

\footnotetext{
${ }^{2}$ Mantova, with its roughly 50,000 inhabitants, is a typical Italian middlesized heritage town, while Pegognaga is a typical Italian small municipality in the $10,000 / 15,000$ inhabitants range.
} 


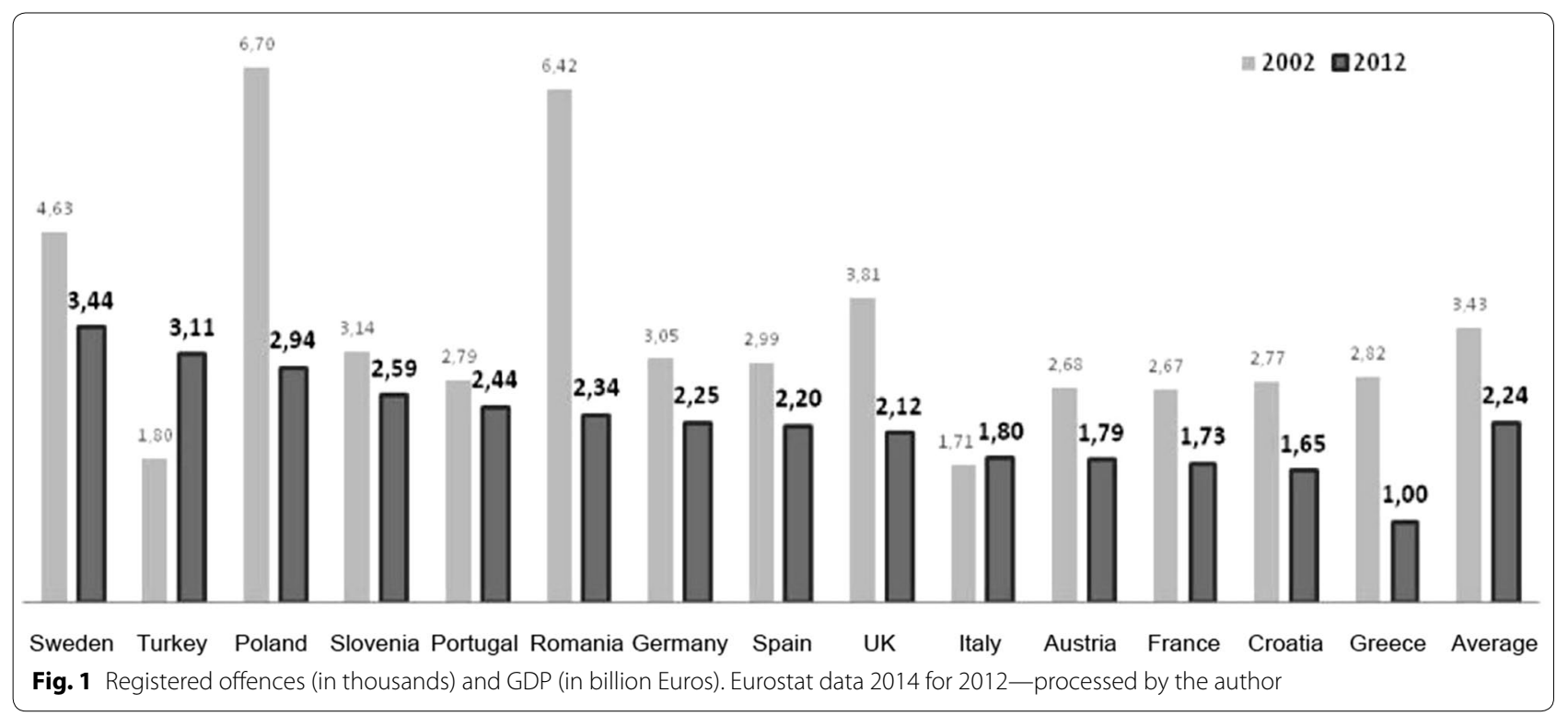

a diversity of institutions and integrated intervention. Criticism has been leveled at these researches for concentrating on the victims of crime, rather than crime itselfalthough it is not always possible to classify anomalous behaviors within the frame of criminal offence.

Other studies assume that urban communities can self-regulate to deal with insecurity and fear. Based on previous surveys conducted in individual urban neighborhoods, rural areas and middle-sized towns, these studies focus on the perceived difficulties and the initiatives taken to enhance community ties, rather than the analysis of crime. Examples of this approach can be found in the patti locali per la sicurezza, (local security agreements), effected in Bologna, Cagliari, Catania and Genoa among others, and described by several authors (Calaresu and Tebaldi 2009, 2015). These studies emphasize the value of local social capital, and the reclamation of the city/town as a common good, through the requalification of commons through the self-management of disused resources, such as the communal gardens in New York, later acknowledged by the local administration (Monaco 2014). In a broader sense, these initiatives aim to rediscover the role of public urban spaces (squares and green areas, etc.) to promote sociability and social cohesion-as was the case with the borough projects recently introduced in the Greater London program of urban regeneration (Nucci 2012).

Hardin (1968) criticized this theory, pinpointing its weakness, the "tragedy of the commons", in the free use of the goods-potentially leading to overuse, degradation, and growing maintenance costs.
Nevertheless, these studies have brought to the fore the theme of Common Goods, material and immaterial, against the neoliberal policies focused on reducing public expenditure, regardless of recurring economic and social emergencies. Elinor Ostrom's works (1990) have stressed the relevance of Common Goods, resulting in the recognition of the Australian Aborigines' pre-capitalist collective rights, although their legalization was effected through written, rather than customary law. In Italy the subject was take up by Rodotà (2013), who defined Common Goods as being both material and immaterial goods, functional to the exercise of fundamental rights and the free development of personality, and as such to be guarded against destructive short-term logics and kept for future generations. This relevantly highlights the contradiction intrinsic to the expanding scope of private right: the monetization of all goods, to be found nowadays in the prevailing and all-pervading financial interests that, for the sake of market efficiency, are at risk of marginalizing all other concerns-both social and productive.

Prevention policies are also hindered by other factors, such as a tendency to shape analysis and action according to political interests; a difficulty to involve central and local administrations in structural prevention policies that coordinate law-enforcement, judiciary and schools; a past history of development provisions entirely focused on urban growth; an ingrained lack of maintenance of goods, services and local infrastructures; the difficulties in programming a policy of regeneration for disused economic and social resources. 


\section{Metropolitan areas and the city of economic primacy: geographical characters}

Modern regional megacities consist of a succession of densely populated centers, urbanized free spaces and small-to-medium towns-a diversity of settlement conditions, equally influenced by an oversupply of property. A neoliberal obsession with efficiency pervades the social fabric, whose less affluent strata aspire to the settled security of daily routine, while their wealthier counterparts still feel unsafe about their goods and personal welfare. Also relevant are the discrepancies between high-end cosmopolitans and those forced to dwell in one place, between the securely and the precariously employed, between those with sound familial ties and the lonely or socially challenged, between those who are culturally attuned to the times and the primary or returning illiterate, between the larger and larger ageing group of the population and the wave of young new immigrants.

While overabundant urban property can attract great investors, unused goods and resources are doomed to disuse in suburban contexts. In great conurbations, a growing transiting population and a decrease of historical population require more social control and a daily routine made of homologated common spaces with shops, streets, squares and standardized food.

The structure of urban population has also changed, with longer life expectancy, a negative RNI (jeopardizing the resident population's capacity for self-renewal), a higher immigration rate from outside the EU, and a growing isolation due to unequal city planning. Even the recovery of traditional family values and the yearning for a bygone society are sliding towards a ritualized struggle against growth based on individuality and a faith in the forces of free economy (Bagnasco and Le Galès 2001).

In this context the boundaries between behaviors perceived as problematic and proper criminal offences become blurry. Crime-fighting is a staple of any political agenda, often used to cover issues of unemployment crisis or nonspecific cultural gaps, or a lack of cooperation in prevention policies, and the responsibilities of local administrators (Barbagli 2008).

These geographical and demographical features apply to smaller towns as well, stemming on the one hand from common factors, such as the presence of disused and deteriorated property. On the other hand, they can be traced to more worrying social factors, such as a shrinking of the population, and the growing tensions of an uncertain future.

Everywhere a primacy of economic interests over concerns of social cohesion changes public morality and fosters intolerance. The privatization and profit-orientation of public services neither makes them less costly nor curtails the state's presence, due to a growing security and military expenditure-as has been long foreseen and denounced in vain.

As early as Jacobs 1961, in the first edition of her book Death and Life of Great American Cities, Jane Jacobs (19162006) described a shifting urban morphology tied to friendliness and perceived safety. A journalist attuned to social issues, Jacobs stresses the importance of sidewalks lined with shops and houses, as well as the "mixed primary uses" of green and public areas. In the same years, while riots erupted in America's black slums, the Mayor of Philadelphia (a different one from the recent promoter of Kindness Day) stated that "the State's borders run nowadays within the city." This describes well other similar situations, such as the Berlin Wall bisecting the former capital of the Reich, the peace lines that until recently divided Catholic and Protestant neighborhoods in Belfast and Londonderry, the minestrewn boulevards between East and West Beirut, the wall separating Jerusalem's Israeli and Palestinian citizens, the recent walls erected to stem the flow of north-bound migrations, and the invisible barriers segregating suburban neighborhoods, as is the case with wealthy white neighborhoods and poor black neighborhoods in Baton Rouge, symbolic of the current flaring of racial issue in the US.

Furthermore, the electronic detection systems, originally devised to protect airports from air piracy between the restricted departure areas and the once unrestricted arrival areas, and to check transiting individuals, have later spread to maximum security detention facilities, banks, shopping malls, urban centers and unsafe neighborhoods. Tools designed to ensure mobility, were later turned into confining and tracking devices.

The city is no longer approached through a door or an arch-but through a listening device, an electronic detection system aimed at checking and insulating suspicious persons and objects. The revolution of private transport and telecommunications has dissolved the sprawling city and its boundless neighborhoods into a hazy conurbation, where even the material opacity of buildings has lost its sense. Physical barriers or time lapse have ceased to isolate the individual, as electronic topology makes "elsewhere" a constant presence. Electronic access protocols have replaced gate access, and databases substitute the sound of door-knocking. Urban expansion is patterned by the subtle rhythms of tyrannical time-planning, by man-machine interface, and by the shifting meaning of physical and geographical boundaries. Everything arrives with no need for departures. Everything is present in the electronic day. Working-time takes center stage, while leisure and unemployed time slid towards the periphery of time and the exile of private life.

In the future, technological innovation and the globalized market's new division of labor should bring to fruition the old tenet that working less means work for 
all, allowing to devote this reclaimed leisure for the nonconsuming activities of knowledge and social interaction.

Against this background, and bearing in mind the question raised by INNES, a need arises to explore the definition and characters of a sociable city as the place of harmonious coexistence, and whether small-to-medium towns can keep their identity within hazy metropoli$\tan$ conurbations, or they share in the social and physical issues of the great cities. The difficulties in answering the citizens' demand for security require a multi-faceted exploration of the very notion of security, with a special attention to current change and the new geopolitical and multicultural tensions.

\section{The case studies of the INNES project}

The approach to the case studies has been twofold.

Firstly, a direct survey has been taken of the factors creating insecurity in the citizens of Mantova and Pegognaga. The research, complemented by meetings and discussions with several institutions and citizens' associations, was documented through two kinds of questionnaires: telephone interviews and 2000 written questionnaires administered to different age-groups, with special focus on school population.

The answers allowed for a diversified description of the perceived insecurity of urban conditions, resulting from physical and behavioral issues. Recurring answers include areas adjoining the railway station, isolated parking lots, dark underpasses, gatherings of aggressive-looking individuals, neglected building sites, disused property and areas, redundant roundabouts and road traffic, the frequent interruption of bike paths.

The younger age-groups also indicated a lack of spaces that can be safely and autonomously reached. This has led to a typological and quantitative survey of the abandoned property in Mantova. The results were organized in two kinds of thematic maps ${ }^{3}$ showing both the extent and position of underused property and areas and building sites (see Figs. 2, 3, 4, 5), and, through the use of suitable sets of symbols, the physical and behavioral issues described by the questionnaires (see Figs. 6, 7).

The next step was an observation of the characters of the two towns-Pegognaga appearing more rooted in the territory, while Mantova presents more contradictions.

\footnotetext{
${ }^{3}$ The maps, shown in an exhibition in Mantova in April 2015, can now be found at the link http://lacittaelaltracitta.wix.com/lacittaelaltracitta, as well as on the weblog lacittaelaltracitta. Also available on the weblog, in both Italian and English, is the study Urbanità e Sicurezza. Urban Safety and Security (ed. Treu 2015), describing the framework and results of the INNES research. Cfr. See the articles of Daniele Bignami, Adelmina dal'Acqua, Stefano Sarzi Amadè, Silvia Marmiroli and Antonia Araldi (Treu 2015).
}

Mantova is a typical heritage town, the capital of a border area touching seven provinces and two regions. The land presents an abundance of water and thrives on agriculture. About $8 \%$ of the population is comprised of immigrants from different backgrounds.

Both towns suffer from strong perceived isolation and neglect, with a lack of material and immaterial ties on a larger scale, emphasized by a scarcity of public and social grounds, especially in the suburbs.

As per the requirements of the INNES project, these issues were compared to other surveys and studies, in particular the surveys commissioned by ANCI, the Association of Italian municipalities, highlighting discrepancies in the perception of security between cities and smaller town, and between income groups, in regard to specific sets of urban sites, such as parking lots and shopping malls (see Figs. 8, 9).

In this sense, even though smaller towns are described as safer than cities, a direct survey of school and adult age groups reveals a variety of forms of fear, depression and uncertainty-and above all the perception of an unchangeable doom, a lack of interest in integrating these small towns into the new network economies while preserving their identities.

Some cases, shown in the attached maps, appear especially relevant.

Lunetta (Mantova) was developed since the Nineteen Sixties as a working-class neighborhood, and subsequently became a dwelling place for transiting individuals and families. The object of two distinct urban renewal projects (Contratti di Quartiere), it remains emblematic of too many unfinished, partially resumed and never completed urban projects. Other Mantuan cases in point are the commercial vacuum in the neighborhood of Valletta Valsecchi, set against the intention to build a new local supermarket adjoining the historical Palazzo Te, and the huge amount of disused or unused industrial property in the northern part of the town, right across the bridge called Ponte dei Mulini.

Pegognaga, despite its more close-knit urban fabric, also shows underused or isolated houses both in central and suburban areas, as revealed especially by the answers of primary school children.

The questionnaire's results indentify the urban conditions impacting on perceived urban security in behavioral factors that don't necessarily qualify as crime, as well as the geographical and morphological characters of a fragmented and divisive urban sprawl. This stresses the urgent need for a rediscovery of material and immaterial historical heritage, as well as the role of schooling in fostering critical thought against the growing supremacy of short-term, market-oriented reasoning. 


\begin{tabular}{|l|l|r|}
\hline \multirow{4}{*}{ SURVEY RESULTS } & TOTAL UNITS & 689 \\
\cline { 2 - 3 } & TOTAL AREA $\left(\mathrm{m}^{2}\right)$ & 3.463 .415 \\
\cline { 2 - 3 } & FLOOR AREA $\left(\mathrm{m}^{2}\right)$ & 1.076 .827 \\
\cline { 2 - 3 } & EXTERNAL AREA $\left(\mathrm{m}^{2}\right)$ & 2.386 .588 \\
\hline
\end{tabular}

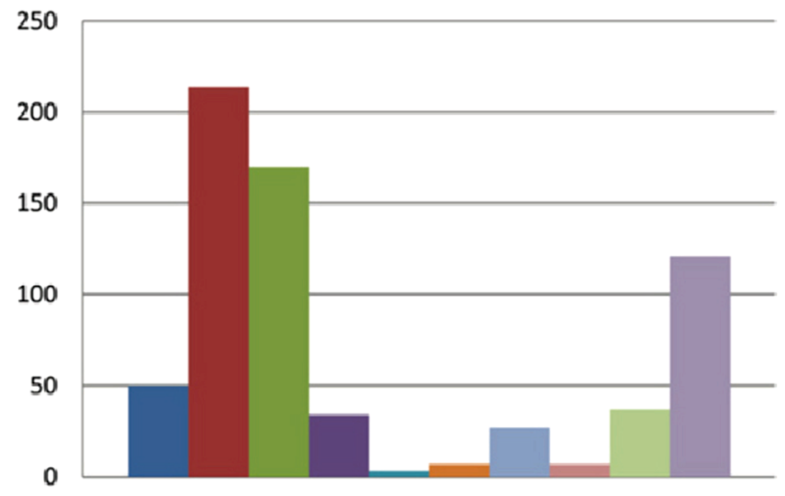

$\begin{array}{lll}\text { - } & \text { F } & \text { Factories } \\ \text { - } & \mathrm{N} & \text { Shops and utilities } \\ \text { - } & \text { R } & \text { Housing } \\ \text { - } & \mathrm{C} & \text { Farmhouses } \\ \text { - } & \mathrm{M} & \text { Military areas } \\ \text { - } & \text { FS } & \text { Railway buildings } \\ \text { - } & \text { S } & \text { Historical buildings } \\ \text { - } & \text { SP } & \text { Public services } \\ \text { CN } & \text { Construction sites } \\ \text { - V } & \text { Green areas }\end{array}$

Surveyed units by category

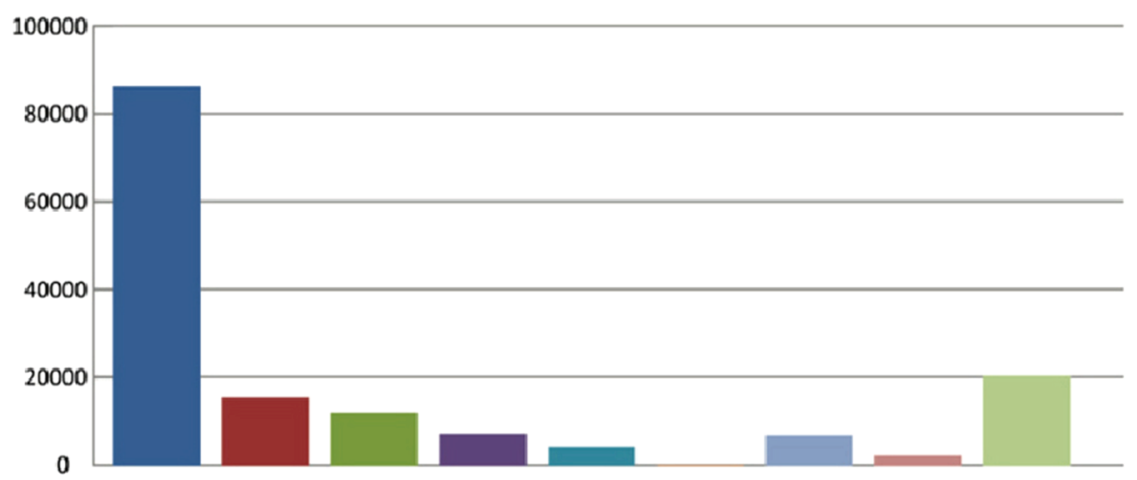

Areas in $\mathbf{m}^{2}$ by group

Fig. 2 Mantova. Survey of disused property—results our elaboration

\section{Interpretation and perspective}

In this sense the research stemming from the INNES project can be defined as a tool to explore and monitor urban needs, and to devise urban regeneration projects through the means of citizen participation, such as actions aimed at bringing new life to neighborhoods and squares.
Security policies need to be managed through the integration of social, economic, planning-focused and cultural approaches around some central issues.

Instead of stressing problematic issues by emphasizing each minor instance of petty crime or intolerance, politicians and information media should support 


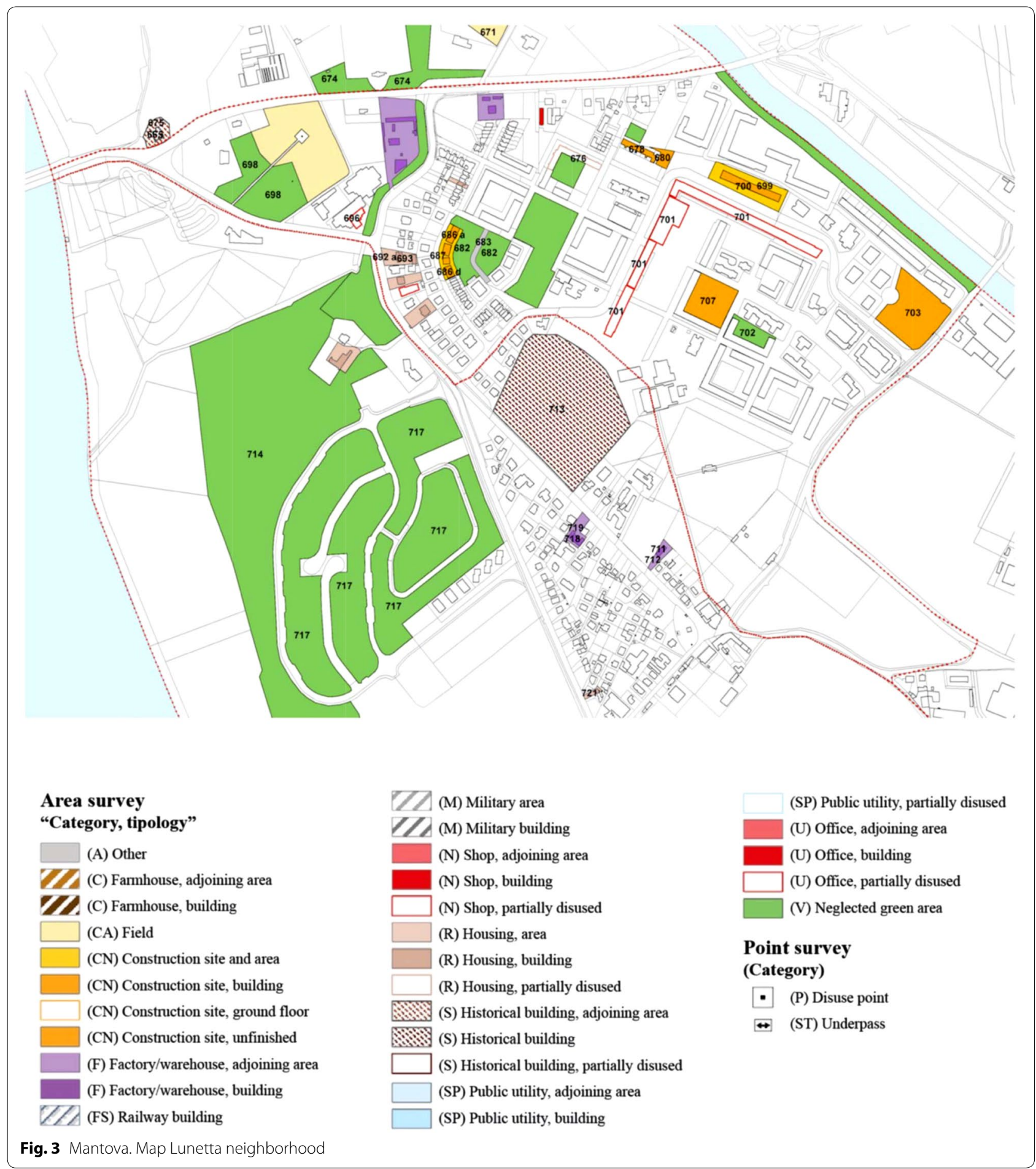

regeneration projects-even outside central areas, to address issues such as the difficulty to organize events similar to Mantova's well-known literary festival (Festivaletteratura) outside the historical center.
In addition, policymakers and planners should actively counteract any further housing, industrial or commercial sprawl, while focusing on programs of urban regeneration centered on the quality of public spaces, as well as 


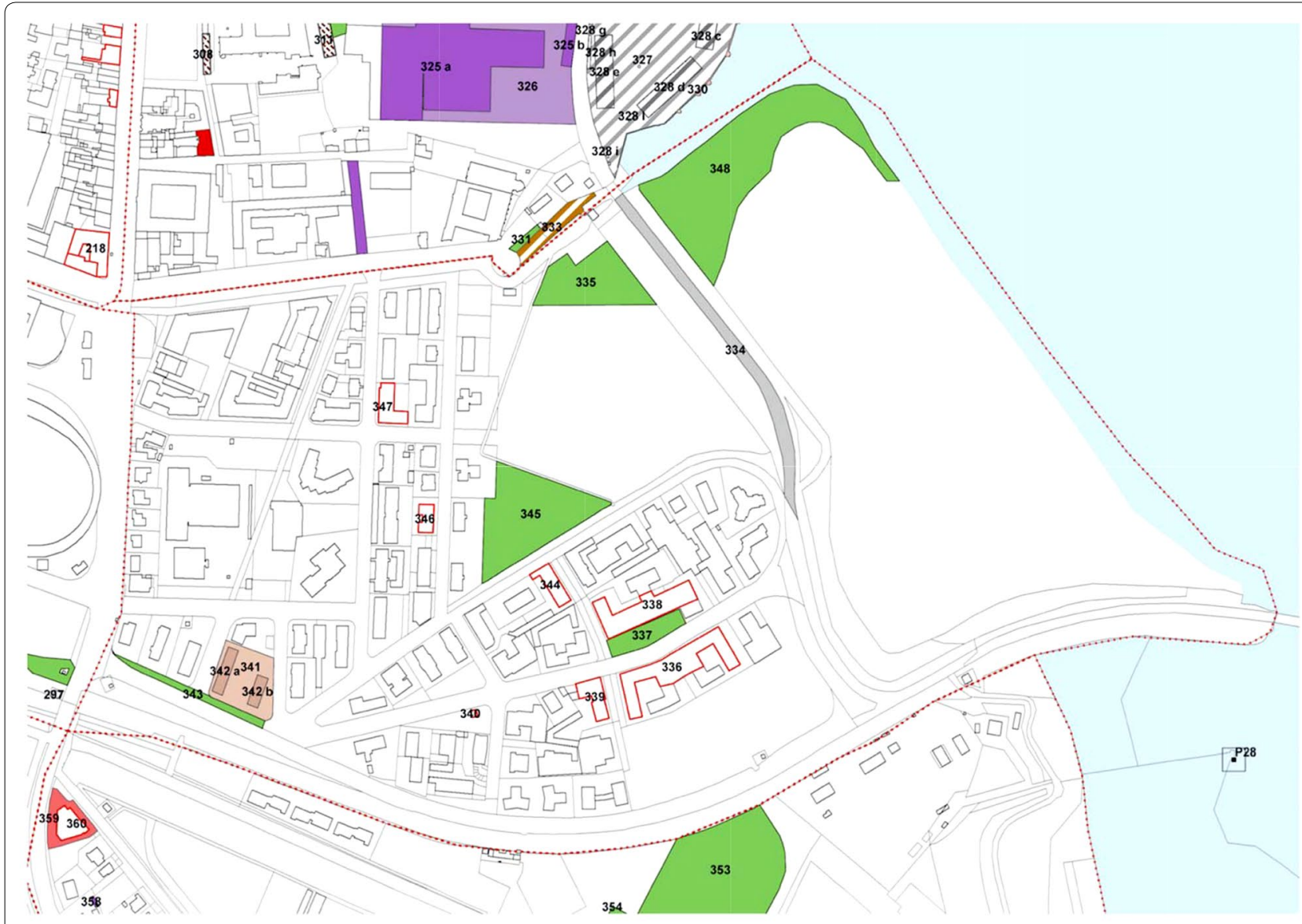

(M) Military area
(M) Military building
(N) Shop, adjoining area
(N) Shop, building
(N) Shop, partially disused
(R) Housing, area
(R) Housing, building
(R) Housing, partially disused
$\square$ (S) Historical building, adjoining area
(S) Historical building
(S) Historical building, partially disused
(SP) Public utility, adjoining area
(SP) Public utility, building

(SP) Public utility, building
(SP) Public utility, partially disused

(U) Office, adjoining area

(U) Office, building

(U) Office, partially disused

(V) Neglected green area

\section{Point survey \\ (Category)}

- (P) Disuse point

$\leftrightarrow \quad$ (ST) Underpass

(CN) Construction site, unfinished

(F) Factory/warehouse, adjoining area

(F) Factory/warehouse, building

CD (FS) Railway building

Fig. 4 Mantova. Map Valletta Valsecchi neighborhood

a renewed network of material and immaterial services and cultural mediation between different generations and cultures.

To this end, systematic cooperation and communication are needed with law enforcement agencies, local government, third-sector associations, schools, research and learning centers.

Research stresses the importance of schooling as a tool to shape, from a very young age, an emotional system able to create for each individual a body of positive 

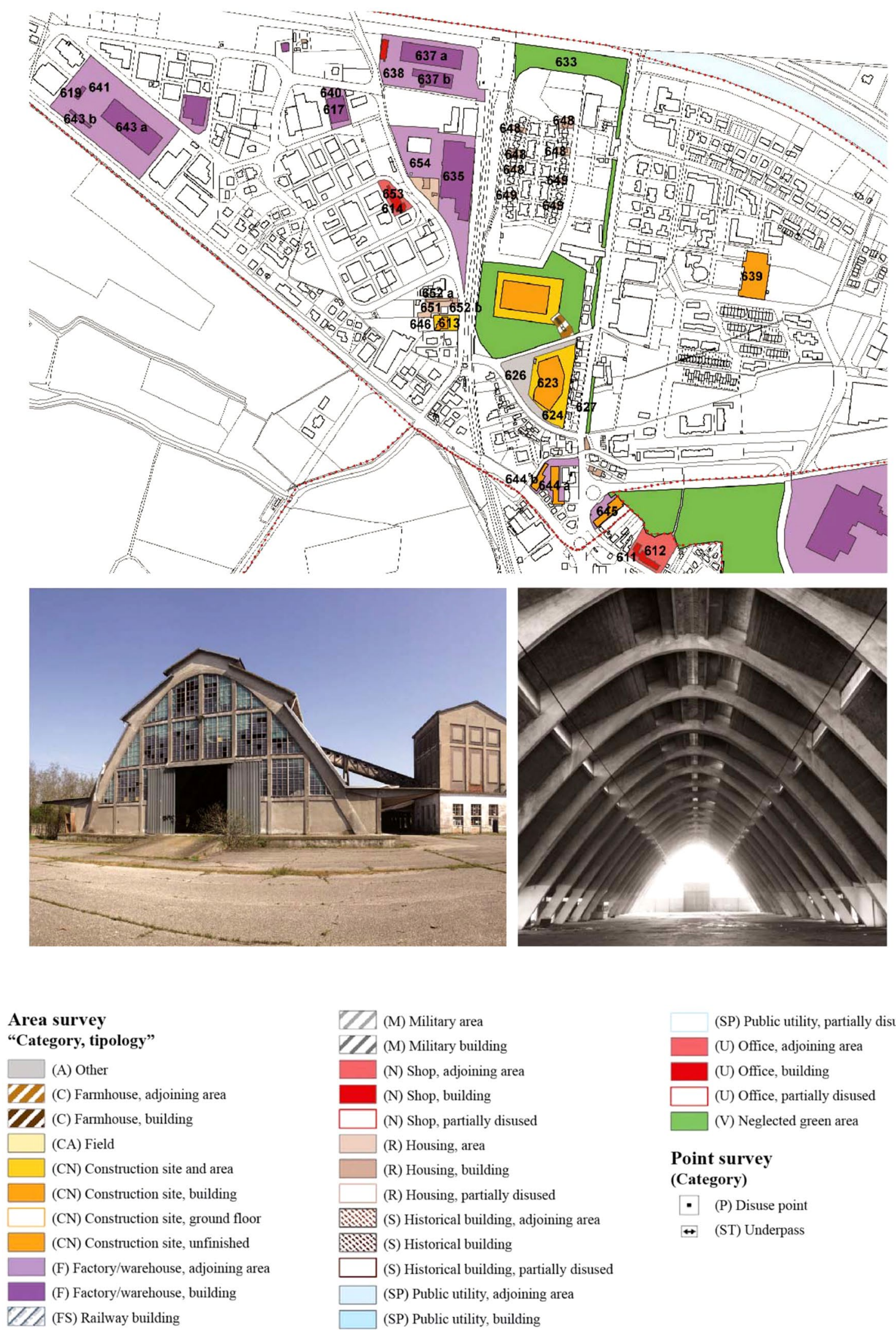

$7 /$ (M) Military area

$1 / 2$ (M) Military building

(N) Shop, adjoining area

(N) Shop, building

(N) Shop, partially disused

(R) Housing, area

(R) Housing, building

(R) Housing, partially disused

䳸滋 (S) Historical building, adjoining area

烈济 (S) Historical building

(S) Historical building, partially disused

(SP) Public utility, adjoining area

(SP) Public utility, building
(SP) Public utility, partially disused

(U) Office, adjoining area

(U) Office, building

(U) Office, partially disused

(V) Neglected green area

\section{Point survey}

(Category)

- (P) Disuse point

$\leftrightarrow$ (ST) Underpass

Fig. 5 Mantova. Map areas north en faces water mill bridge 


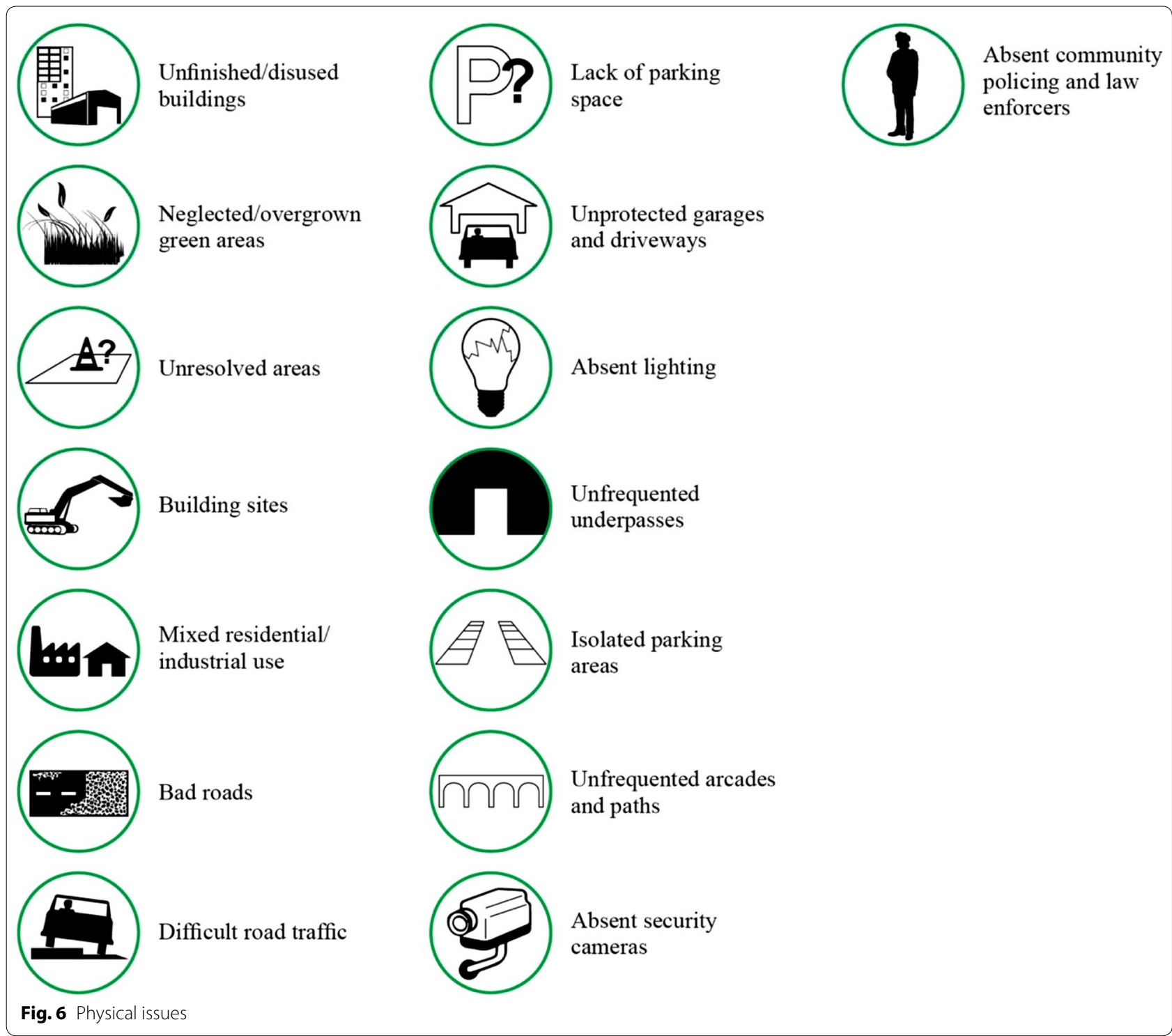

memories-thus founding and fostering a belief system that will guide the future young adult towards rational and sensible behavior. (Salvadori and Rumiatl 2005) This refers to the behavioral diversity, also involving the parents, where children from diverse backgrounds only experience shared initiatives at school.

At working level, there is an urgent need to rediscover goods to develop, common spaces and community ties. However, priorities should not single out individual excellent buildings or areas, but take into consideration all the patterns, also aesthetical, consistent with environmental sustainability and the settlement's morphology and resiliency, as a whole and in its interrelated parts.

As already stated, the dynamics of disuse and deterioration greatly differ in cities and small-to-medium towns, especially those removed from great metropolitan areas. The distinction does not apply when exploring the risk of marginalization of entire areas, or the loss of the historical heritage and material culture that shaped the quality of our towns and urbanized areas. The alternative to efficiency-oriented neoliberal logics is challenging, but unavoidable. To contrast a tendency to planning choices growingly focused on competition and gain, and heedless of the waste of human resources, will require an effort will also be required to network all urban hubs with the infrastructural system on different levels and modes, and projects of urban regeneration that include concerns of quality and security, in a continuous and coordinated institutional action, in smaller towns as well as larger cities (Lefebvre 2009). 


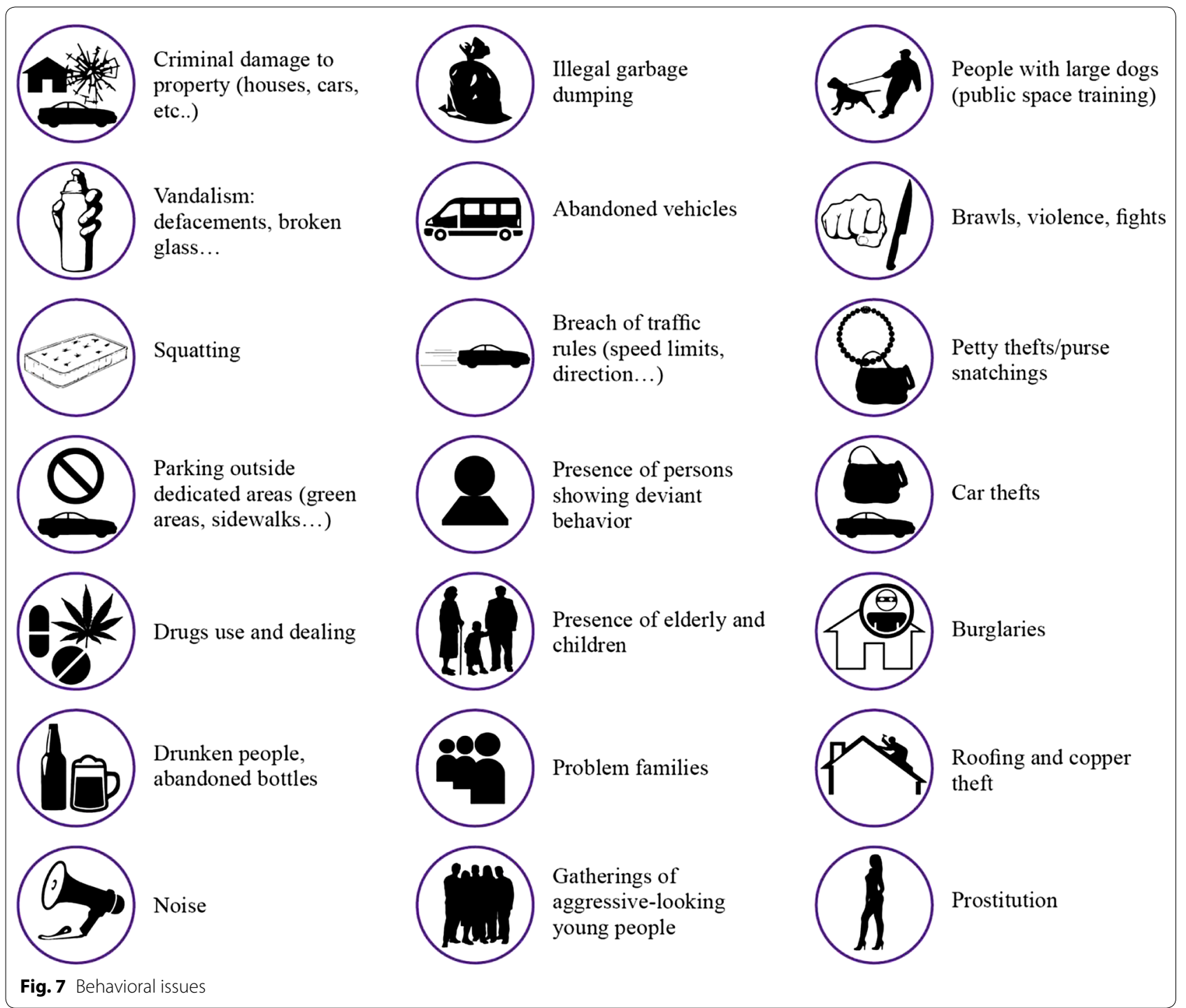

Since the 1990s, many European cities have prioritized urban renewal, with connecting programs for urban neighborhoods that involve the citizens and the upgrade (sometimes through short-time solutions) of common spaces like squares and green areas.

This scenario envisions variously sized cities and towns embedded in a material and immaterial long-distance network, as well as enjoying short-distance routes safely connecting dwelling places to sites of common interest and ground-floor local utilities-as already happens in some cities, eg. Greater London (Nucci 2012). The goal, besides revitalizing public spaces, is that of promoting unplanned personal interaction in places and along routes designed to allow optional socialization (Gehl 2011). As the Greek Agora hosted the discussion of public and private themes, so nowadays, in the words of The Athens Charter (CIAM VII, Bergamo 1949), the city begins in its public spaces, the hubs where new focus can find its place, and new relations and sensations accrue.

This prospect requires a long-term commitment, bringing together a diversity of parties to rebuild a safe urban space comprising the whole city and a large urbanized area. This kind of (often densely peopled) context involves choices and actions no less complex than the reconstruction of urban spaces in the wake of a natural catastrophe (Giglia 1997). In the modern paucity of social ties, the reconstruction of urban spaces calls for redevelopment programs including actions of social renewal and a strengthening of community ties on multiple levels. The inescapable social changes ahead are bound to generate 


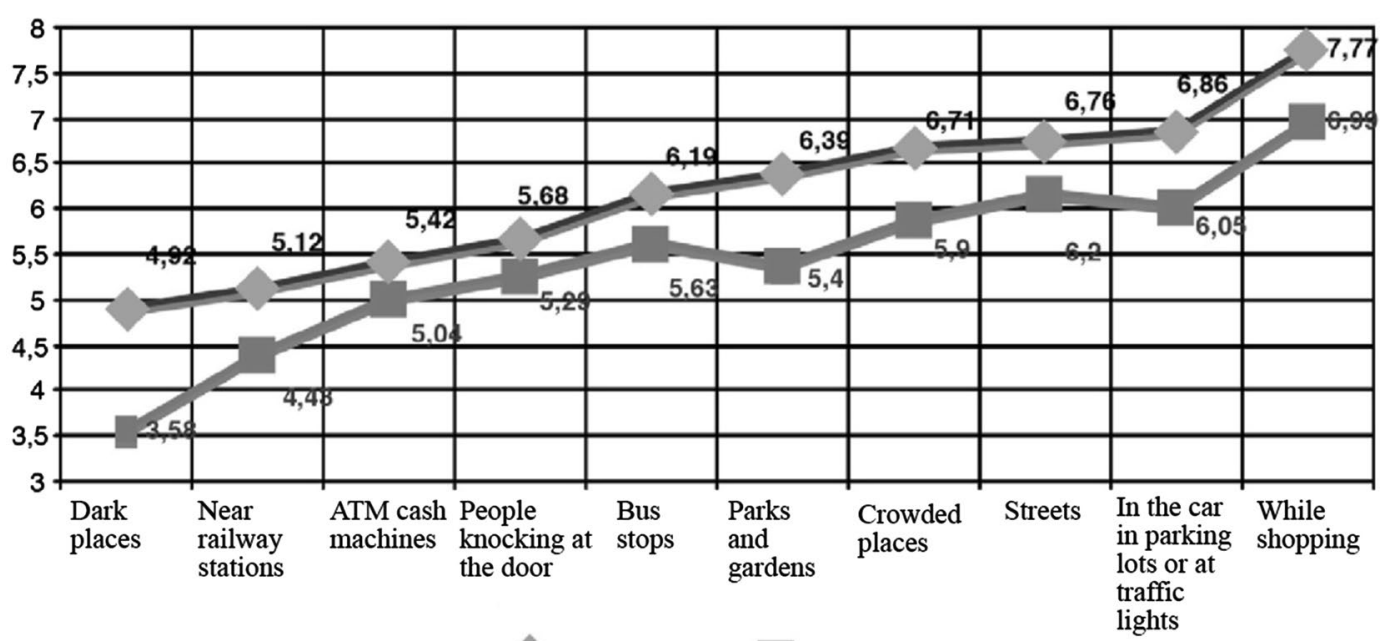

Fig. 8 Small towns and large cities. Perceived site security: ranging from 1 (maximum security) to 10 (maximum insecurity). Cittalia Anci Ricerche (2008)

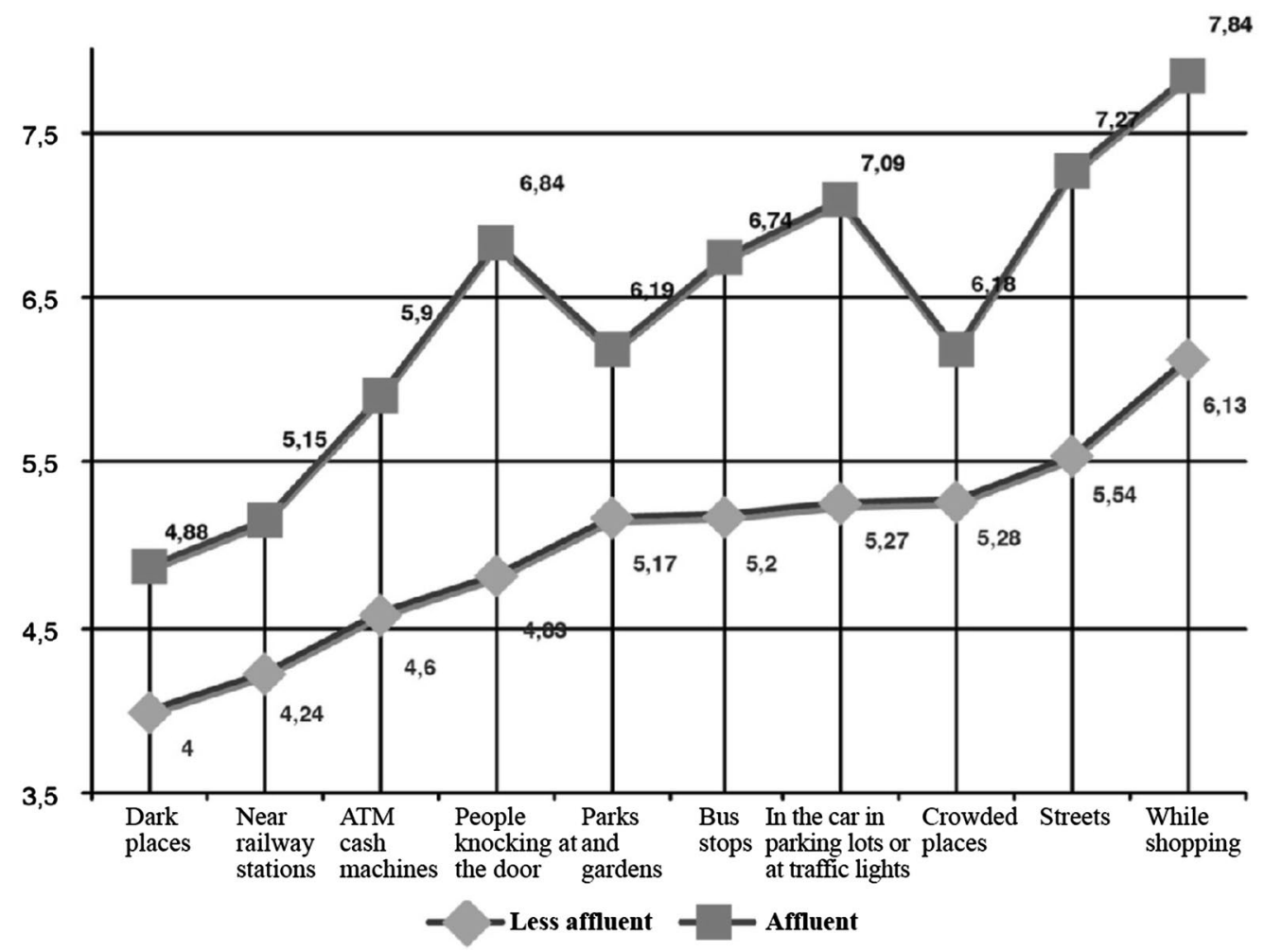

Fig. 9 Less affluent and affluent. Perceived site security: ranging from 1 (maximum security) to 10 (maximum insecurity) Cittalia Anci Ricerche (2008)

a growing demand for participation in the many opportunities that integration and accessibility offer and must ensure to all.
Authors' information

Maria Cristina Treu, full professor in urban planning at Politecnico of Milan, where she was Director of Documentation Center, Prorector of Politecnico and Vice President Politecnico Fondation. She was teacher in a course of lectures 
on the Environmental Planning and, recently, on the Urban design and Urban Landscape.

Her more recent publications are "Città, Salute e Sicurezza", Politecnica Series of Maggioli Editor, 2009, "Per una Città Socievole", La città e l'altra città Series, 2014 and "Urban safety and security", La città e l'altra città Series, Maggioli Editor, 2015.

Up to date she was codirector of La città e l'altra città Series, President of Fiorella Ghilardotti Association about immigration questions and consilior of metropolitan agency of public local transport (TPL).

\section{Acknowledgements}

The Fondazione del Politecnico di Milano provides the institutional framework links with Europe for the project "Intimate Neighbourhood Strengthening (INNES), An Italian Crime Prevention Pilot Programme for small cities" (Project with co-financing of Europe Union on the Specific Programme Prevention of and Fight against Crime-Annual Work Programme 2011, part of the general Programme 2007-2013 "Security and Safeguarding Liberties", approved by Europe Union with Council Decisions 2007/125/JHA, Directorate General Affairs European Commission). The research team of the Politecnico di Milano, Campus of Mantova, together with the local FDE Institute of Criminology provide the research. Professor MC Treu is the project's scientific director.

The essay refers to MC Treu's speech at the Mantova international conference "Urbanity" (26-29 November 2015), as well as the research contained in Urbanità e sicurezza. Urban safety and security (Treu 2015).

\section{Competing interests}

The author declares that she has no competing interests.

Received: 14 September 2016 Accepted: 13 October 2016

Published online: 21 October 2016

\section{References}

Amendola G (ed) (2003) Una città senza paure. Dalle politiche per la sicurezza a quelle per la vivibilità. Comune network, Firenze

Amendola G (2015) Emozioni urbane. Odori di città. Liguori, Napoli

Augè M (2008) Non luoghi. Introduzione a una antropologia sulla surmodernità. Elèuthera, Milano

Augè M (2013) Le nuove paure. Che Cosa temiamo oggi. La Feltrinelli, Milano Bagnasco A, Le Galès P (eds) (2001) Le città nell'Europa contemporanea. Liguori, Napoli

Barbagli M (2008) Immigrazione e sicurezza in Italia. II Mulino, Bologna Battistelli F (2008) La fabbrica della sicurezza. FrancoAngeli, Milano

Battistelli F (2016) La sicurezza e la sua ombra. Terrorismo, panico, costruzione delle minacce. Donzelli, Roma
Bauman Z (1999) La società dell'incertezza. II Mulino, Bologna

Bauman Z (2002) La società individualizzata. Come cambia la nostra esperienza. II Mulino, Bologna

Beck U (1986) Risikogesellschaft. Auf dem Weg in eine andere Moderne. Suhrkamp, Frankfurt

Calaresu M (2013) La politica di sicurezza urbana. II caso italiano (1994-2009). FrancoAngeli, Milano

Calaresu M, Tebaldi M (2009) Valutare la democrazia introduzione alla qualità democratica. Arcane, Roma

Calaresu M, Tebaldi M (2015) Local security policies and protection of territory: an analysis of the Italian experience (2007-2009). City, Territory Archit 2(1):1

Cardia C, Bottigelli C (2011) La città sicura. Hoepli, Milano

Cittalia-Anci Ricerche (2008) I piccoli comuni e la sicurezza. Analisi della percezione del senso di insicurezza dei cittadini nei piccoli comuni. Fondazione Anci Ricerche, Roma, pp. 38,40

Gehl J (2011) Life between buildings. Island Press, London

Giglia A (1997) Crisi e ricostruzione di uno spazio urbano. Guerini Associati, Milano

Hardin G (1968) The tragedy of commons. Science 162(3859):1243-1248

Jacobs J (1961) Death and life of great American cities. Random House, Toronto

Karrer F (2003) La polizia di prossimità. La partecipazione del cittadino alla gestione della sicurezza nel panorama internazionale. FrancoAngeli, Milano

Lefebvre H (2009) Le droit à la ville. Anthropos/Economica, Paris

Monaco D (2014) Avant garden, II paesaggio dei Community Gardens. Palazzo Bonaretti Editore, Novellara. http://lacittaelaltracitta.wix.com/lacittaelaltracitta. Accessed 1 Sept 2016

Nucci L (2012) Verde di prossimità e disegno urbano. Le open space strategies e i local development frameworks dei $32+1$ Boroughs di Londra. Gangemi Editore, Roma

Ostrom E (1990) Governing the Commons. The Evolution of Institutions for Colectieve Action. Cambridge University Press, Cambridge

Pavarini M (2006) L'amministrazione locale della paura. Ricerche tematiche sulle politiche di sicurezza in Italia. Carrocci, Roma

Rodotà S (2013) II terribile diritto. Studi sulla proprietà privata e i beni pubblici. II Mulino, Bologna

Salvadori L, Rumiatl R (2005) Nuovi rischi e vecchie paure. II Mulino, Bologna

Treu MC (ed) (2009) Città, salute, Sicurezza. Strumenti di governo e casi studio. La gestione del rischio. Maggioli Editore, Sant'Arcangelo di Romagna

Treu MC (2015) (ed) Urbanità e sicurezza. Urban safety and security. Maggioli Editore, Santarcangelo di Romagna. http://lacittaelaltracitta.wix.com/ lacittaelaltracitta. Accessed 1 Sept 2016

Véron J (2008) L'urbanizzazione del mondo. II Mulino, Bologna

\section{Submit your manuscript to a SpringerOpen ${ }^{\circ}$ journal and benefit from:}

- Convenient online submission

- Rigorous peer review

- Immediate publication on acceptance

- Open access: articles freely available online

- High visibility within the field

- Retaining the copyright to your article

Submit your next manuscript at $\mathbf{s p r i n g e r o p e n . c o m ~}$ 